\title{
Parallel Sampling of Nanoliter Droplet Arrays for Noninvasive Protein Analysis in Discrete Yeast Cultivations by MALDI-MS
}

\author{
Dominik Haidas ${ }^{1}$, Marta Napiorkowska ${ }^{1}$, Steven Schmittt ${ }^{1}$, and Petra S. Dittrich ${ }^{1, *}$ \\ ${ }^{1}$ Bioanalytics Group, Department of Biosystems Science and Engineering, ETH Zürich, Mattenstr. 26, 4058 Basel, \\ Switzerland, and ${ }^{2}$ Bioprocess Laboratory, Department of Biosystems Science and Engineering, ETH Zürich, \\ Mattenstr. 26, 4058 Basel, Switzerland
}

Brazzein production and purification. A $5 \mathrm{ml}$ YPD preculture of brazzein-secreting $K$. phaffii was cultivated until stationary phase and used to inoculate $500 \mathrm{ml}$ YPD medium at a dilution of 1:1000. Upon reaching stationary phase, the production culture was centrifuged $(3,500 \mathrm{~g}, 20 \mathrm{~min})$, the supernatant was harvested, adjusted to $\mathrm{pH}$ of 7.0 , and filtered through a bottle-top filter $(0.22 \mu \mathrm{m}$ pore size, polyether sulfone membrane, Stericup, Merck Millipore). The purification was done using an ÄKTA explorer chromatography system (GE Healthcare) operated with Unicorn software version 5.31. The supernatant was loaded onto an XK 16/20 column packed with $10 \mathrm{ml}$ of Ni Sepharose Excel (GE Healthcare) and equilibrated with 5 column volumes (CV) of wash buffer $(500 \mathrm{mM} \mathrm{NaCl}, 20 \mathrm{mM}$ sodium phosphate, $\mathrm{pH}$ 7.4). The column was washed with $10 \mathrm{CV}$ of wash buffer before eluting the peptide with $3 \mathrm{CV}$ of elution buffer $(500 \mathrm{mM} \mathrm{NaCl}, 500 \mathrm{mM}$ imidazole, $20 \mathrm{mM}$ sodium phosphate, $\mathrm{pH}$ 7.4). The eluent was loaded onto an XK 50/30 column packed with $300 \mathrm{ml}$ of Sephadex G-25 (GE Healthcare), which was equilibrated with $5 \mathrm{CV}$ of desalting buffer ( $20 \mathrm{mM}$ ammonium carbonate, $\mathrm{pH} 7.4$ ), and eluted with $2 \mathrm{CV}$ of desalting buffer. The eluted fractions corresponding to brazzein (monitored at $280 \mathrm{~nm}$ absorbance) were collected, pooled, frozen at $80^{\circ} \mathrm{C}$ for $2 \mathrm{~h}$, and lyophilized using a manual vacuum freeze-dryer (Alpha 1-2 LD plus, Martin Christ Gefriertrocknungsanlagen GmbH, Osterode am Harz, Germany) connected to a vacuum pump (RC6, Vacuubrand, Wertheim, Germany). The freezedried peptide powder was dissolved in $1 \mathrm{ml}$ of phosphate buffer ( $10 \mathrm{mM}$ sodium phosphate, $1.8 \mathrm{mM}$ potassium phosphate, $137 \mathrm{mM} \mathrm{NaCl}$, and $2.7 \mathrm{mM} \mathrm{KCl}, \mathrm{pH} 7.4$ ) and subjected to preparative highperformance liquid chromatography (HPLC) using a Prontosil PREP 2025 C18 column $(10 \mathrm{~mm}, 250 \mathrm{~mm}$ $\times 20 \mathrm{~mm}$ ) with a guard column (Bischoff Chromatography, Leonberg, Germany). The column temperature was maintained at $30^{\circ} \mathrm{C}$. The mobile phase was composed of $0.1 \%$ TFA in water (solvent A) and $0.1 \%$ TFA in acetonitrile (solvent B). The flow rate was maintained at $10 \mathrm{ml} \mathrm{min}^{-1}$. The column was equilibrated on $0 \%$ B for 6 min followed by the linear gradient from $0 \%$ B to $56 \%$ B for $40 \mathrm{~min}$. The fractions corresponding to brazzein (monitored at $210 \mathrm{~nm}$ absorbance) were pooled, frozen at $-80^{\circ} \mathrm{C}$ for $2 \mathrm{~h}$, and lyophilized as before. The freeze-dried peptide powder was dissolved in $1 \mathrm{ml}$ of water and stored at $-20^{\circ} \mathrm{C}$. For quantification of brazzein, the brazzein sample was subjected to a reversed-phase HPLC (Agilent Technologies) using a ReproSil-Pur C18-AQ column ( $3 \mathrm{~mm}, 150 \mathrm{~mm} \times 2.1 \mathrm{~mm}$; Dr. Maisch $\mathrm{GmbH}$ ). The mobile phase was composed of $0.1 \%$ TFA in water (solvent $A$ ) and $0.1 \%$ TFA in acetonitrile (solvent B) and was run on $0 \%$ B for 3 min followed by a linear gradient from 0\% B to $50 \%$ B for 25 min at a flow rate of $0.3 \mathrm{ml} \mathrm{min}^{-1}$. The sample injection volume was $50 \mu \mathrm{l}$ and the column temperature was maintained at $40{ }^{\circ} \mathrm{C}$. The concentration was measured using the area under the curve at $205 \mathrm{~nm}$ and brazzein-specific molar extinction coefficient $\left(258506 \mathrm{M}^{-1} \mathrm{~cm}^{-1}\right){ }^{1,2}$ 


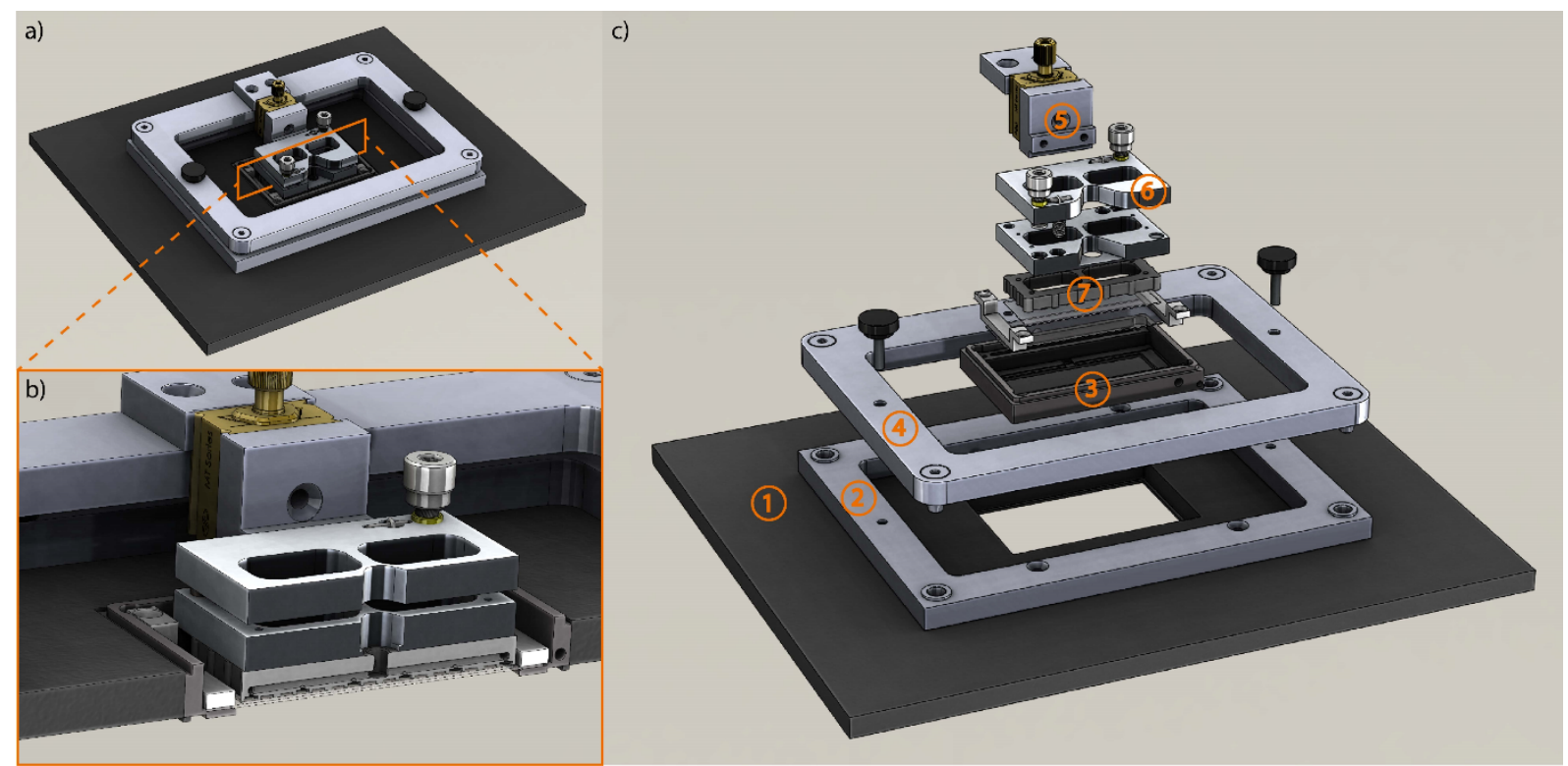

Figure S1. System for aligning the top and bottom plate. a) Overview of the whole system. b) Cut and zoom in the top and bottom slide holder. c) Individual components of the plate alignment system mounted on the microscopy stage (1). The bottom part of the system consists of a frame (2) that is fixed to the microscopy stage. At the four edges of this frame, the bottom part of locating block sets (TPCAT12C, Misumi) are inserted. The bottom slide holder (3) can be placed directly into the center of the microscopy stage, and serves additionally as oil bath. The upper part of the alignment systems consists of the upper frame (4), which is fixed to a manual precision linear stage (5) (MT X, Newport) to allow for vertical movement. To also correct for horizontal tilts, we integrated a tilting stage (6), custom-made from a kinematic mirror mount (KMS, Thorlabs). At the edges of the upper frame the top parts of the locating block sets with tapered pins (TPCAT12C, Misumi) are placed. The top plate of $60 \times 25 \mathrm{~mm}^{2}$ size is hold in the upper frame using vacuum. Therefore, 3D-printed hollow ring (7) (custom design, printed by Protolabs, material: Accura ABS black) is used and connected to vacuum supply tubing and the vacuum pump (here not shown). 
Table S1. Recipe of the HCD medium. For further information, see ref. (3). The individual solutions were premixed and stored at $4{ }^{\circ} \mathrm{C}$. Before the experiment the $\mathrm{HCD}$ medium was mixed together as specified by the volume ratio.

\begin{tabular}{l|c|c|c} 
& $\begin{array}{c}\text { Volume ratio } \\
(\mathbf{\%})\end{array}$ & $\begin{array}{c}\text { Mass concentration } \\
(\mathbf{g} / \mathbf{L})\end{array}$ & $\begin{array}{c}\text { Molar concentration } \\
(\mathbf{m M})\end{array}$ \\
\hline Glucose solution & $\mathbf{2 2 . 5}$ & & \\
\hline Glucose & & 200 & 1110.1 \\
\hline
\end{tabular}

\begin{tabular}{l|c|c|c}
\hline Glutamate solution & $\mathbf{8 . 1}$ & & \\
\hline Monosodium glutamate & & 50 & 295.6 \\
\hline
\end{tabular}

\begin{tabular}{|c|c|c|c|}
\hline Amino acid solution & 9.9 & & \\
\hline Glutamine & & 5 & 34.0 \\
\hline Histidine & & 1.75 & 11.3 \\
\hline Leucine & & 5.5 & 41.9 \\
\hline Lysine & & 6 & 41.0 \\
\hline Methionine & & 2 & 13.4 \\
\hline Phenylalanine & & 2.5 & 15.1 \\
\hline Serine & & 1.875 & 17.8 \\
\hline Threonine & & 1 & 8.4 \\
\hline Uracil & & 2 & 17.8 \\
\hline YNB solution & 27.0 & & \\
\hline YNB & & 15 & 108.6 \\
\hline Inositol solution & 2.1 & & \\
\hline Inositol & & 10 & 55.5 \\
\hline Buffer solution & 2.0 & & \\
\hline MES & & 195.2 & 1000.0 \\
\hline Ammonium sulfate & & 1 & 7.6 \\
\hline $\begin{array}{l}\text { Sodium dihydrogen } \\
\text { phosphate }\end{array}$ & & 1 & 8.3 \\
\hline
\end{tabular}


Table S2 List of chemicals

\begin{tabular}{|c|c|}
\hline Chemical & Supplier \\
\hline Acetonitrile & Sigma-Aldrich \\
\hline Ammonium bicarbonate & Sigma-Aldrich \\
\hline Ammonium sulfate solution ( $3.2 \mathrm{M}$ ) & LabForce, Muttenz, Switzerland \\
\hline Dextrose & Sigma Aldrich \\
\hline D-Glucose & Sigma-Aldrich \\
\hline Di-potassium hydrogen phosphate & Carl Roth \\
\hline Di-sodium hydrogen phosphate & Carl Roth \\
\hline Glutamic acid & Sigma Aldrich \\
\hline HFE 7500 & 3M, Maplewood, USA \\
\hline Histidine & Sigma Aldrich \\
\hline Imidazole & Applichem GmbH, Darmstadt, Germany \\
\hline Inositol & Sigma Aldrich \\
\hline Leucine & Sigma Aldrich \\
\hline Lysine & Fluka (Honeywell), Charlotte, USA \\
\hline MES & $\mathrm{TCl}$ Deutschland $\mathrm{GmbH}$ \\
\hline Methionine & Fluka (Honeywell),Charlotte, USA \\
\hline Monosodium glutamate & Sigma Aldrich \\
\hline Peptone & Becton Dickinson \\
\hline Phenylalanine & Sigma Aldrich \\
\hline Potassium chloride $(\mathrm{KCl})$ & Applichem GmbH, Darmstadt, Germany \\
\hline Potassium di-hydrogen phosphate & Applichem GmbH, Darmstadt, Germany \\
\hline Serine & Sigma Aldrich \\
\hline Sodium chloride ( $\mathrm{NaCl})$ & Applichem GmbH, Darmstadt, Germany \\
\hline Sodium dihydrogen phosphate dihydrate & Carl Roth, Merck KGaA \\
\hline Threonine & Sigma Aldrich \\
\hline Trifluoroacetic acid (TFA) & Sigma-Aldrich, Thermo Fisher \\
\hline Uracil & Sigma Aldrich \\
\hline Yeast extract & Becton Dickinson \\
\hline Yeast nitrogen base (YNB) & Becton Dickinson \\
\hline Yeast extract peptone dextrose (YPD) broth & Sigma Aldrich \\
\hline Zeocin & Thermo Fisher \\
\hline a-cyano-4-hydroxy-cinnamic acid (CHCA) & Sigma-Aldrich \\
\hline
\end{tabular}


References:

(1) Anthis, N. J.; Clore, G. M. Sequence-Specific Determination of Protein and Peptide Concentrations by Absorbance at 205 Nm. Protein Sci. 2013, 22 (6), 851-858.

(2) Pelillo, M.; Cuvelier, M. E.; Biguzzi, B.; Gallina Toschi, T.; Berset, C.; Lercker, G. Calculation of the Molar Absorptivity of Polyphenols by Using Liquid Chromatography with Diode Array Detection: The Case of Carnosic Acid. J. Chromatogr. A 2004, 1023 (2), 225-229.

(3) Roberts, T. M.; Kaltenbach, H.-M.; Rudolf, F. Development and Optimisation of a Defined High Cell Density Yeast Medium, BioRvix, doi: 10.1101/846006. 